\title{
LOS INCENDIOS COMO AMENAZA DE LOS TEATROS. EL OTRO INCENDIO DEL TEATRO LÓPEZ DE AYALA EN BADAJOZ Y LAS CIRCUNSTANCIAS EXCEPCIONALES QUE AMENAZARON SU RESTAURACIÓN Y SUPERVIVENCIA
}

FIRES LIKE A MENACE FOR THEATERS. THE OTHER FIRE OF TEATRO LOPEZ DE AYALA IN BADAJOZ AND EXCEPTIONAL CIRCUMSTANCES THAT THREATENED ITS RECOVERY AND SURVIVAL

\author{
Sergio SUÁREZ RAMÍREZ \\ Universidad de Valladolid \\ sergio.suarez@uva.es \\ Ángel SUÁREZ MUÑOZ \\ Universidad de Extremadura \\ asuarez@unex.es
}

Resumen: Los teatros debieron resistir frente a múltiples adversidades, no todas relacionadas con el desarrollo de la actividad que amparaban. Los materiales con que se construían y decoraban fueron sus grandes enemigos. Solo como resultado de episodios inesperados y, muchas veces, ajenos a las propias representaciones escénicas, mejoraron sus condiciones. Relatamos a continuación las circunstancias que rodearon el incendio que se produjo en el Teatro López de Ayala de Badajoz durante la Guerra Civil española. 
Palabras claves: Teatro. Actividad escénica. Guerra Civil. Badajoz. Incendio.

\begin{abstract}
Theaters had to resist multiple adversities which, not all, are related to development of their activities. The built and decorated materials were their main opponent. Only as a result of unexpected episodes and, often different to the own scenic representations, the theaters improved their conditions. Below, we report the circumstances of the "Teatro Lopez de Ayala" fire that happened in Badajoz during Spanish Civil War.
\end{abstract}

Key Words: Theater. Theatrical productions. Civil War. Badajoz. Fire.

\title{
1. INTRODUCCIÓN
}

Siempre el cuidado de los locales dedicados a las representaciones teatrales generó no pocas dificultades y quebraderos de cabeza a las autoridades, propietarios, empresas y propios actores. Los teatros solían pertenecer a los ayuntamientos y su mantenimiento resultaba muy costoso entre remozamientos, decorados, utillaje y otros gastos materiales, como para incluir, además, medidas en previsión de incendios. El avance de los años y las privatizaciones no cambian sustancialmente en lo referido a las medidas de seguridad.

En el siglo XVIII los locales teatrales habían sufrido muchas transformaciones que dejan atrás los antiguos corrales de comedias. En general, la precariedad de los medios económicos en que se movió el teatro favoreció que se mantuvieran infinidad de inadecuaciones y escasas condiciones materiales, que se agravaron con el frecuente cierre prolongado de estos locales.

Un repaso a la historia de los locales teatrales nos revela la frecuencia con que los incendios asolaban estos espacios escénicos, hasta el punto de convertirse en verdadera preocupación para las autoridades públicas. Fueron diversas las disposiciones encaminadas a tomar precauciones con las luces, que se utilizaban para iluminar los escenarios y los espacios de acceso en los teatros; o con los fumadores, ya que en estos locales eran muy abundantes los materiales de fácil combustión, por el exceso de 
madera empleada en la construcción de los mismos, por las tarimas, las cortinas y los lienzos de decoración, que los adornaban. Muy conocidos fueron los incendios sufridos por los teatros de Zaragoza en 1778, Murcia en 1779, La Casa de las Comedies de Barcelona en 1787 o el coliseo del Príncipe de Madrid en 1802, por citar algunos casos.

En el siglo XIX se produjeron algunos avances en las condiciones y características de los teatros. Pero, en lo que respecta a lo material, siguieron siendo muy precarios. Continuó existiendo un elevado riesgo de incendio, derivado principalmente de la iluminación, que solía ser muy insuficiente. En general, se utilizaba como combustible aceite y velas de sebo hasta que, con el devenir de los años, se acabó introduciendo el gas a lo largo de la segunda mitad del siglo. Los escenarios solían estar iluminados con velas de sebo para asegurar una iluminación constante y regular durante el tiempo que duraban las representaciones, entre tres horas y media o cuatro. Igualmente, podemos indicar que la iluminación de la sala se conseguía mediante una lucerna central que, además de luz, dejaba caer sobre los espectadores aceite y mucho humo.

Un estudioso de prestigio como Sepúlveda (1888: 309-310) nos ha dejado una descripción bastante exacta de cómo se desarrollaba el rito, como él lo define, de encender ese artilugio principal:

Media hora antes de levantarse el telón, bajaba la araña lenta y majestuosamente, girando sobre la maroma del torno y derramando lluvia, acompañada de aceite industrial, compuesto con mejunjes venenosos, para que los encargados de la alimentación no cayeran el deseo de llevárselo a sus mujeres [...] Un farolero encendía los quinqués; otro daba vueltas a las llaves; otro hacía girar en redondo la araña; y cuando después de subir y bajar las torcidas y saltar en el ensayo unos cuantos tubos, parecía la araña un sol macilento de guardarropía, se daba aviso al torno por medio de un silbido, que el público embobado repetía con júbilo, y el artefacto luminoso empezaba a subir con la misma lentitud y majestad con que habia bajado al patio. Durante el trayecto, solian apagarse algunos quinqués y entonces era un oprobio el humo apergalloso (sic) que despedian los agujeros, otras veces saltaban 
los tubos en lluvia de vidrios sobre los espectadores descuidados, cuando no corría hilo a hilo el aceite de los recipientes...

Con este procedimiento estaban más que justificadas las protestas de los espectadores por las manchas o por el aire irrespirable producido por el humo.

Durante la segunda mitad del siglo XIX se llevó a cabo una profunda remodelación de los teatros. Podemos afirmar que la mayoría de los teatros que funcionan hoy en día, y que acreditan una larga trayectoria vital, fueron construidos o reformados entonces. Es verdad que han sobrevivido muy pocos teatros en relación con el número tan considerable de ellos que llegaron a funcionar en nuestro país. Unos desaparecieron como consecuencia de la especulación urbanística; otros fueron transformados en recintos para fines diversos y un buen número de ellos fueron pasto de las llamas.

Se dictaron leyes y normativas para paliar esa plaga. Se introdujeron modificaciones importantes en cuanto a su estructura: mayor parcelación de los edificios, especificaciones más concretas sobre la anchura que debían tener los pasillos, ancho de las puertas, la instalación de un telón de acero que aislara el escenario de la sala, precisamente para reducir los efectos de los incendios que habitualmente se producían en el espacio escénico, etc. Se generalizó la iluminación por gas hasta que, a finales del XIX y principios del XX, fue una realidad la iluminación eléctrica.

\section{LOS INCENDIOS EN EL TEATRO LÓPEZ DE AYALA}

Como ya hemos documentado en otras publicaciones anteriores -realizadas al amparo del Centro de Investigación de Semiótica Literaria, Teatral y Nuevas Tecnologías de la UNED, dirigido por el profesor José Romera Castillo-, la ciudad de Badajoz vio cumplido su deseo de figurar en los itinerarios de las empresas teatrales más importantes durante la segunda mitad del siglo XIX cuando el 30 de octubre de 1886 inauguró su Teatro López de Ayala (Suárez, 1996, 1997, 2002 y 2003; Suárez Muñoz y Suárez Ramírez, 2002, 2006).

Fue el resultado de un proceso que se alargó más de lo debido. Desde 1861 existía un informe que sugería que la modernización de la ciudad más 
poblada de Extremadura, entre otras medidas, debía incluir la construcción de un teatro digno. A partir de 1864 esa sugerencia del Gobernador se convirtió en proyecto serio y ejecutable.

El Ayuntamiento apostó decididamente por esa construcción, a pesar de las dificultades económicas que irán surgiendo en una ciudad con muchas necesidades básicas, aún por cubrir. El recorrido trazado nos informa sobre concursos de obras parcelados, interrupciones por falta de presupuesto, concursos desiertos, ampliaciones frecuentes del presupuesto inicial y, finalmente, venta a los constructores para saldar las deudas acumuladas.

Lo cierto es que, a pesar de los inconvenientes, Badajoz verá hecho realidad un sueño: disponer de un teatro que supliera la precariedad del que venía funcionando desde 1800, cuando se habilitó el antiguo Hospital de la Piedad, privatizado con la desamortización de Mendizábal. Se trataba del teatro denominado Principal o del Campo de San Juan, por ser el más importante y para indicar su ubicación (esquina Plaza de España, antiguamente Plaza de San Juan, con calle del Obispo, en su denominación actual), respectivamente.

La inauguración del teatro fue todo un acontecimiento social. Su nombre final como Teatro López de Ayala se debió al deseo de rendir homenaje al insigne político y escritor, diputado por Badajoz en varios periodos constitucionales, aunque nacido en Guadalcanal, cuando esta población formaba parte de la provincia de Badajoz, antes de la definitiva delimitación provincial, llevada a cabo durante la regencia de María Cristina, tras la muerte de Fernando VII. Como sabemos, la intención no fue otra que la configuración de un país menos centralizado, lo que dio lugar a la división del territorio nacional en provincias. Teniendo en cuenta factores geográficos, históricos y de racionalidad administrativa, se fijó para Extremadura una superficie que prácticamente se conserva hoy día. Mayores repercusiones tuvo la división de la antigua provincia de Extremadura en dos demarcaciones provinciales: Cáceres y Badajoz. Esto supuso una reordenación de municipios con relación a las provincias limítrofes, cediéndose unos e incorporándose otros. En el caso concreto de Badajoz, pueblos antes sevillanos como Monesterio o Fregenal de la Sierra, pasaron a pertenecer a ella, mientras que Guadalcanal pasó a Sevilla e Hinojosa del Duque a Córdoba.

La noche del 30 de octubre de 1886 no se pudo olvidar durante mucho tiempo, a pesar de que no se celebró una función inaugural con el 
boato que la ocasión exigía. Desde las páginas del Diario de Badajoz $\mathrm{n}^{\mathrm{o}}$ 1.259 de 2 de noviembre se criticó duramente el que la empresa propietaria del teatro no hubiera respondido en la inauguración de la forma que un acontecimiento, tan grande como ese, requería y era esperado por la ciudadanía, representada no sólo por los vecinos de Badajoz, sino por las muchas personas que desde todos los puntos de la provincia y del vecino Portugal se dieron cita en la ciudad para asistir a tan histórico acto.

Además, no se entendió la ausencia de actos paralelos que dieran más espectacularidad a la que ya de por sí aportaba el edificio y la representación teatral en él efectuada, dada la muy desahogada posición económica de sus dueños. Se llegó a decir que la inauguración de cualquier café habría resultado más solemne, aunque menos económica. No hubo ni música, ni lectura de poesías, ni ramillete de flores para las damas, ni invitaciones a los poetas y artistas de la localidad, ni a la prensa, ni el popular aperitivo. Nada, pues, de lo acostumbrado en solemnidades parecidas que ayudan a preparar el ánimo hacia el éxito y el porvenir, no ya únicamente de la temporada, sino de los años futuros que se le desean al espacio que se está inaugurando.

Para el Diario de Badajoz, antes citado, la función con la que abrió sus puertas por primera vez el Teatro López de Ayala, en la que se puso en escena de la zarzuela Campanone, se resintió de esa falta comentada, repercutiendo negativamente, además, sobre las personas que menos culpa tenían: el arquitecto, el pintor escenógrafo y los actores. Estos últimos salieron cohibidos a la escena; aquéllos, ni siquiera recibieron la felicitación de rigor por el trabajo realizado. Igualmente, en esta función inaugural el público se quejó mucho.

En relación con las localidades, sabemos que hubo numerosos altercados, debidos a los que no acababan de ocupar sus asientos por no conocer el sitio, ni entender los colocadores las letras ni el número para conducirles a sus localidades. Además de las 332 butacas, se habían colocado numerosas sillas en los pasillos, afeando el conjunto y molestando al público, para acallar el disgusto de muchos a quienes injusta o indebidamente se les había prometido una localidad. La empresa fue muy criticada por la anómala distribución de las localidades, sacrificando para sus intereses los del público que pagaba. También se censuró las largas filas y preferentes localidades ocupadas por gente extraña a la población, con olvido de los propios que se quedaron en sus casas u ocuparon 
incómodos asientos. Con eso se puso en riesgo el que los residentes en Badajoz, excluidos, no se prestasen a ocupar durante la temporada teatral localidades que no habían de volver a ser ocupadas por quienes esa noche lo hicieron.

También el público se quejó de la falta de alumbrado que desconsoló sobre todo a las señoritas, tan interesadas en estudiar el lujo y mérito de los artistas, seguía comentando el periódico. No se encontró explicación a la existencia de muchos tubos rotos y ahumados, no sólo en la escena sino en el resto de dependencias del teatro. En definitiva, la función pareció más una de final de temporada que lo que era, el inicio de una y la inauguración de un nuevo coliseo. Por eso, los dueños quisieron, después de la inauguración, mejorar aún más las condiciones del Teatro López de Ayala y solicitaron a Madrid los aparatos precisos para aumentar el número de luces; también tomaron las medidas necesarias para evitar el intenso frío que, a medida que avanzaba la temporada, se hacía sentir en el teatro, sobre todo al levantarse el telón.

La Crónica del día 28 de octubre de ese año 1886, en su número 1.819 , dedicó dos páginas al nuevo teatro. Tras una reseña histórica en la que resumió las circunstancias por las que fue pasando el proyecto de construcción, se detallaron sus características y se describieron para general conocimiento. Aunque es una información muy extensa, nos parece la mejor manera de conocer el teatro que se había construido en la ciudad:

Situado en la Plaza de Minayo, a la que mira la fachada principal del mismo, afecta la forma de un pentágono irregular, cuyos lados dan al paseo de San Francisco, el de la derecha entrando, y el de la izquierda a la CasaHospicio [...]

Las butacas, en número de 332, ocupan la parte central de la herradura, dejando un paso circular inmediato a las plateas, para facilitar la circulación, ofreciendo otro en el medio, que directamente atraviesa las filas de butacas, desde la puerta central de entrada hasta la orquesta.

El arco de proscenio o embocadura de once metros de ancho por 9,70 de alto y artística y primorosamente ornamentado, sirve de marco al telón de boca, que constituye una 
perfecta y acabada obra de arte. Unos cortinajes rojos que un Pierrot separa, para dar vista al fondo del cuadro, decoran el templo del arte, que se descubre en segundo término, representado por una columnata circular con su correspondiente entablamento de estilo dórico griego y ocupado por las nueve musas una de las cuales, la de la Comedia, se adelanta a recibir a Calderón de la Barca, que con traje talar, la cruz de Santiago en el costado y un libro en la mano, se dirige a ella, a fin de ser coronado con la que un genio alado viene a depositar con tal objeto a los pies de un Dios Apolo que ocupa sobre un clásico pedestal el hemiciclo descrito.

El tercer término de este cuadro lo constituye un bonito y variado panorama que ofrece a la vista del espectador la histórica torre de Espantaperros, los cubos de la Puerta de Palma, el puente de este nombre y algún otro detalle de sabor local que no desentona sino que, al contrario, viene a dar relieve al cuadro.

Otro no menos artístico y perfecto ofrece el techo, en cuyo centro un grupo de musas envueltas en bonito celaje representan la música, la poesía y el baile y cuyo circuito ocupa una balaustrada a la que se hallan asomados un Mefistófeles de un lado y de otro una pareja de majos de la ópera de Goya, vestidos con el traje clásico y echados sobre un rico tapiz de la misma época. Esta balaustrada descansa en su parte circular sobre una escocia artísticamente decorada con caretas de ornamentación y medallones que ostentan los bustos de D. Ramón de la Cruz, Moreto, Calderón, Cervantes, Moratín, Lope de Vega y Tirso de Molina.

[...] Y, finalmente, para terminar esta ya larga descripción, diremos que 47 grandes mecheros vulcanos, sustentados por elegantes candelabros y la batería de 20 luces del proscenio, difunden la claridad por todos los ámbitos de la platea; y que las escaleras y galerías también se hallan suficientemente alumbradas. 
En relación con el tema que nos ocupa, referido a los incendios en los teatros, y más concretamente en el Teatro López de Ayala, queremos destacar el párrafo, omitido en la descripción anterior, que hace mención a este asunto:

Las precauciones contra incendios no han sido menos atendidas que las de la estética. Cubre la embocadura por completo, un telón metálico, montado con arreglo a las prescripciones legales y al nivel de cuya parte superior se halla establecido un tubo de hierro taladrado con pequeños y numerosos agujeros que en caso necesario mojarían aquél convenientemente y verterían una copiosa lluvia sobre el tablado de proscenio, produciendo un aislamiento completo entre la sala y el escenario. Dos bocas contra incendios, provistas de sus respectivas mangas y situadas en los ángulos de intersección de los palcos de proscenio con la embocadura a la altura de un metro sobre el tablado, otra en el fondo del escenario y una espaciosa puerta en el mismo que abre hacia afuera en un espacio libre de toda edificación, completan las precauciones adoptadas en la previsión de estos terribles siniestros y ofrecen la seguridad de ser fácil y prontamente sofocado el que por cualquier evento pudiera iniciarse.

Ya hemos comentado las precarias condiciones de conservación de los teatros y la combustibilidad de los materiales empleados en su construcción: exceso de madera, cortinas del escenario, lienzos de la decoración, etc. En este sentido, este nuevo teatro se exponía a sufrir los riesgos que comportaba su construcción:

El arco de proscenio o embocadura de once metros de ancho por 9,70 de alto y artística y primorosamente ornamentado sirve de marco al telón de boca, que constituye una perfecta y acabada obra de arte. Unos cortinajes rojos que un Pierrot separa, para dar vista al fondo del cuadro, decoran el templo del arte [...]

Los tabiques divisorios de los palcos, de madera pintada de 
color nogal, con filetes negros, ostentan en su parte superior un bordón de terciopelo rojo y terminan en un adorno de hojas de acanto de color blanco y dorado. El fondo de los palcos se halla entapizado con papel igualmente rojo y adornado de oro.

Como podemos comprobar, presentaba decoraciones en telas aterciopeladas y sobre madera, igual que gran parte de la estructura del propio teatro, tal y como constatamos en la memoria primitiva:

En las divisiones de palcos y antepalcos carpintería de taller pintada. Suelo forjado y entarimados en escenario, platea y palcos y antepalcos, cubiertos los forjados con pizarra y baldosa común, según el uso de la pieza, paso o sala. Escaleras de ida y vuelta y de ida sola y de caracol con pasamanos de hierro forjado. Tabiques de madera en las divisiones de palcos y antepalcos [...].

Todo esto que hemos venido comentando predisponía necesariamente para que el teatro acabara siendo pasto de las llamas, a poco que hubiera un descuido o se dieran una serie de circunstancias que impidieran una reacción inmediata. En la función celebrada la noche del 13 de enero de 1893 ocurrió un episodio lamentable en la aún corta vida del Teatro López de Ayala, a causa del sistema que todavía se utilizaba para su alumbrado.

Ese viernes se despidió la compañía de ópera dirigida por Modesto Subeyas Basch con Los Puritanos, ópera en tres actos con libreto de Carlos Pépoli y partitura musical de Vicenzo Bellini. Todo discurría con normalidad, la misma que había caracterizado las representaciones de esta compañía desde que debutara la víspera de Reyes. Pero, en un momento, un incidente alteró esta normalidad de la que hablamos, influyendo en el desarrollo de la función. Como sucede siempre con estas cosas, de manera inesperada, dos quinqués colocados en el escenario se inflamaron y faltó muy poco para que se propagara a todo el edificio. Gracias a la intervención de un bombero, presente en la función, se pudo apagar el petróleo en el acto, sin que las llamas prendieran un bastidor próximo. Se logró que todo quedara en el susto, pero la preocupación entre el público asistente y los aficionados al teatro en general fue en aumento, ya que, al parecer, con ese 
habían sido ya dos los casos de incendio, producidos en el Teatro López de Ayala. El temor, entonces, era que pudiera producirse alguno más.

Con tal motivo se dirigió un telegrama al Ministro de la Gobernación para que hiciera valer los reglamentos. En el telegrama venía a decirse que en Badajoz había luz eléctrica para el alumbrado público y particular desde hacía más de dos años y, a pesar de esto, el teatro se iluminaba con petróleo. En La Región Extremeña del 19 de enero de 1893, número 2.213, se comentó que el Teatro López de Ayala no volvería a abrir sus puertas hasta que no tuviera instalada la luz eléctrica, se hubiera colocado un telón metálico y el edificio reuniera las medidas de seguridad que exigía el reglamento, puesto que, también se supo, de las tres puertas que comunicaban el paraíso con las demás localidades, que en caso de urgencia podían facilitar la salida, se habían cerrado dos por orden de los dueños. Ya unos meses antes, en El Orden de 14 de noviembre de ese mismo año, número 462, se comentó que el Gobernador Civil había ordenado a los dueños del Teatro López de Ayala que dotaran el edificio de los útiles y materiales necesarios para evitar los efectos de un incendio. Se colocaron para ello las bocas de riego, mangueras y doce espuertas de arena en los sitios designados por los bomberos. Al servicio de bomberos se le equipó con un sencillo y vistoso uniforme, estando organizados y dirigidos por el señor Sampérez, promotor del Gimnasio de la ciudad.

La Región Extremeña del 24 de marzo de 1894 en su número 2.582, dio a conocer que los dueños del teatro, por fin, se habían convencido de la necesidad de establecer el alumbrado eléctrico. En abril aún se planteaban dudas al respecto y se confiaba en que el Gobernador cumpliría su ofrecimiento acerca del alumbrado del teatro y que este no abriría si no se sustituía el petróleo por la luz eléctrica. El día 10 de mayo de este año se verificó la prueba de la luz eléctrica en el teatro. La sala estaba brillantemente iluminada, tanto que se pensó en la posibilidad de eliminar su intensidad en algo durante la representación, para poder apreciar los efectos escénicos. Los focos colocados fueron 52 que, con los 6 de la embocadura del escenario, componían 58 y, como la potencia de cada uno era de 25 bujías, se conseguía alumbrar la sala por medio de 1.400 de estas. El escenario también estuvo muy alumbrado. El acontecimiento dio motivo a las autoridades para celebrarlo como una auténtica fiesta a la que asistieron el Gobernador, el Alcalde y representantes de la prensa. 


\section{EL OTRO INCENDIO DEL TEATRO LÓPEZ DE AYALA}

Ni que decir tiene que el Teatro López de Ayala, desde el año de su inauguración, acaparó la vida escénica de la localidad. Incluso se prestó como espacio público para otros cometidos: conferencias, mítines políticos, acontecimientos sociales (homenajes o actos benéficos), etc. Con la irrupción del cinematógrafo en las primeras décadas del siglo XX se fue reconvirtiendo en sala de proyecciones, coincidiendo con el descenso de los espectáculos y representaciones teatrales. Pero continuó siendo el espacio de referencia cultural de la ciudad.

El 14 de agosto de 1936, sin embargo, todo cambiará. Ese día se produjo la entrada de manera violenta en la ciudad de los sublevados contra el régimen republicano, iniciado con el golpe de estado del 18 de julio, que se prolongará durante algunos años, en ese episodio de la historia de nuestro país conocido como la Guerra Civil.

Ese día contempla uno de los episodios más tristemente célebres de toda la contienda. La historia lo ha recreado con diferentes matices, según el bando contendiente que lo refiriera, pero todos lo conocen como el día de la matanza de Badajoz.

Quienes se han ocupado de describir los dramáticos acontecimientos de la entrada de las tropas rebeldes en la ciudad apenas mencionan, como un hecho episódico más, los sucesos que otorgaron protagonismo al Teatro López de Ayala.

La ocupación del Cuartel de la Bomba, donde el coronel Puigdengolas, responsable de la defensa de la ciudad, había instalado el puesto de mando, y la del Baluarte de Santiago (conocido popularmente como Memoria de Menacho) para despejar la zona y permitir el acceso del II Tabor de Regulares de Ceuta por las brechas del edificio de Correos y puerta Pilar, fueron consideradas claves por el Comandante Castejón para la ocupación definitiva de la ciudad.

Todos estos enclaves que hemos mencionado se sitúan próximos al Teatro López de Ayala en un radio no mayor a 300 metros. Es decir, que por azares del destino, el teatro se encuentra en el camino que las tropas invasoras han escogido para adentrarse en la ciudad (ver anexo I).

Siendo así, es fácilmente comprensible que varios milicianos (defensores de la ciudad), que estaban siendo obligados a replegar sus posiciones, se hicieran fuertes en el Teatro López de Ayala. Sin entrar a 
considerar las diferentes versiones que existen sobre el episodio que se sucede a continuación, podemos considerar como la más fiable la que apunta a que varios legionarios, pertenecientes a las tropas asaltantes, mediante granadas de mano, incendiaron el teatro para provocar la salida de los allí atrincherados, al tiempo que se acompañaban de fuego, metralla y apoyo aéreo. Así lo afirman Pilo, Domínguez y De la Iglesia (2010: 102) en su libro sobre la matanza de Badajoz.

Estos mismos autores dan cuenta de los periodistas internacionales que al día siguiente entran en la ciudad para narrar lo que ven a su paso. Mario Neves (Diario de Lisboa), Jacques Berthet (corresponsal de Le Temps en Lisboa) y Marcel Dany (agencia Havas), con la autorización que reciben en la Comandancia por parte de Agustín Carande Uribe, destacado falangista de Badajoz, inician su recorrido por algunas calles de la ciudad.

Uno de los primeros lugares de mayor relevancia que visitan fue la Plaza de Minayo, conocida entonces también como la Plaza de Moreno Nieto, por situarse en ella un busto en su memoria. En esta plaza se encuentra ubicado, como entonces, el Hospital Provincial, sobre el que habían caído varias bombas que provocaron el destrozo de varias dependencias de enfermería. También observan que el Teatro López de Ayala, a escasos metros del Hospital, se encuentra completamente destruido por el fuego. En nota adicional los autores añaden que:

El teatro López de Ayala no se incendió a consecuencia de los bombardeos, sino por la acción de los legionarios de la V Bandera cuando, tras lograr entrar en Badajoz, fueron atacados por fuego de fusilería por un grupo de milicianos que se habian parapetado en dicho teatro. Para acabar con la resistencia, lanzaron bombas de mano hacia el interior que, al estallar, provocaron el incendio que dejó prácticamente destruido el teatro.

Otro periodista Jean d'Esme, corresponsal del periódico francés $L$ Intrasigeant envía desde Badajoz un artículo (ver anexo II) que vio la luz el día 27 de agosto de 1936 en el número 20750, página 3. El título ya es suficientemente ilustrativo: Badajoz l'epouvantée (Badajoz la aterrorizada). El comienzo del párrafo subtitulado Á travers les ruines (Entre las ruinas) hace referencia a la impresión que provocó en el 
periodista la contemplación del teatro arrasado por el fuego. Incluimos la traducción cuidada:

Voy a pie por Badajoz. Todas las calles son literalmente un enjambre de tropas - legionarios, fusileros marroquies, guardias civiles, falangistas, aviadores-.

En todas las ventanas, en todas las puertas, en todos escaparates banderas blancas. En la calle San Juan -una auténtica calle española, estrecha y empinada, que concentra las principales tiendas de la ciudad-observo las dependencias robadas, saqueadas, vacías de muebles, escaparates arrancados, puertas rotas, suelos cubiertos de escombros de todas clases.

Después me dirijo al teatro.

Tras su fachada aún en pie y que podría engañar, el incendio que lo ha devastado, acaba de extinguirse. Pasando por encima de las vigas carbonizadas, humeantes todavía, deslizándome entre los pliegues de las paredes desvencijadas, llego a la sala principal. Y de repente ante mis ojos el más fantástico, el más conmovedor espectáculo de devastación. Algo indescriptible: toneladas de escombros y de hierros torcidos, ennegrecidos, forman un caos de restos que se apilan hasta el segundo piso en el que me encuentro. $Y$ de este montón de hierros y piedras sobresalen dos piernas, calcinadas...

\section{LA RECONSTRUCCIÓN DEL TEATRO LÓPEZ DE AYALA Y LAS RAZONES DE SU SUPERVIVENCIA}

En el Archivo de la Diputación Provincial de Badajoz se encuentra un expediente con la portada de la Secretaría de la Diputación Provincial de Sevilla relativo a la reconstrucción del Teatro López de Ayala. Se compone de 35 documentos, que detallamos en el anexo III, y que dan una idea de la tramitación administrativa seguida en la solicitud de autorización para la reconstrucción del Teatro López de Ayala. Nosotros, para no alargar en exceso este artículo, nos referiremos solamente a uno de esos documentos: el de la peritación que hacen las Compañías Aseguradoras un años después, 
prácticamente adornada de apreciaciones subjetivas e interesadas.

La tramitación se prolongó durante más de dos años desde que ocurrió el incendio. Solo a partir del mes de noviembre de 1938 los propietarios dispondrán de la pertinente autorización para reconstruir el teatro. Esta tardanza administrativa está más que justificada por las circunstancias en que se encontraba el país, todavía en plena guerra civil que, como sabemos, no se dará por acabada hasta abril de 1939.

La cronología del proceso de reconstrucción permite diferenciar varios momentos:

a) Peritación de los daños e inicio del proceso. Toda la tramitación se iniciará casi un año después del incendio, concretamente a partir de abril de 1937, cuando las Compañías de Seguros del Teatro López de Ayala realizan sus pertinentes peritaciones.

b) Proyecto de reconstrucción. A partir del mes de enero de 1938 y hasta septiembre de ese año se desarrolla todo el proceso de tramitación administrativa para conseguir las autorizaciones oportunas.

- Mayo de 1938: Informe justificativo para el inicio de las obras, elaborado por el arquitecto Luis Murillo y solicitud del representante de los propietarios, Carlos A. Doncel, para que se periten y valoren los daños.

- Julio de 1938: Instancia y proyecto de reconstrucción, requisitos para iniciar el expediente, informe sobre conducta y propiedades del representante de los propietarios, requerimientos sobre si el Ayuntamiento de Badajoz autoriza las obras por estar la parcela libre de alineación o proyectos de reformas urbanísticas, valor catastral anterior al incendio, informe favorable de la fiscalía de la vivienda y valoración de los daños por el arquitecto provincial.

- Agosto de 1938: recopilación de toda la información requerida y su correspondiente tramitación administrativa.

- Septiembre de 1938: autorización definitiva para la reconstrucción del teatro, aunque con trámites pendientes que deben ser completados. c) Reconstrucción a cargo de los propietarios, por cuenta propia, a la espera de alguna subvención o ayuda proveniente del Estado, cuando este elabore una Ley que aborde la reconstrucción del país, siempre que incluya un apartado referido a locales de espectáculos.

La documentación encontrada es muy importante para conocer detalles claves tanto de la propia reconstrucción o de las características y condiciones del teatro, como de las causas del incendio, aunque en esto 
último todo esté muy mediatizado por la percepción que aporta solo una de las partes del conflicto que, como es lógico, achaca toda la culpa al otro bando.

Incluso, se aprecia una evolución interesada del representante de los propietarios que es quien tramita todo el expediente de solicitud de autorización. En los primeros escritos no entra en consideraciones políticas o juicios de valor. Sin embargo, cuando el expediente está concluido y la autorización aprobada, a pesar de que se indica claramente que "no pueden informar sobre el grado de adhesión al Movimiento Nacional, por no existir personas que le garanticen, y únicamente se muestra desde su iniciación, simpatizante con el Movimiento", Carlos A. Doncel, consciente de que sus representados no obtendrán ayuda alguna para la reconstrucción del teatro, a pesar de todo el largo proceso vivido, hará apreciaciones de evidente calado político al afirmar que "dicho edificio fue incendiado por los rojos antes de la huida' y que 'fue vilmente quemado por la horda roja el día de su huida", completamente coincidente con las primeras peritaciones que, interesadamente, hicieron las compañías aseguradoras para ahorrarse las indemnizaciones correspondientes.

Aunque eso es así, y por tanto con las precauciones oportunas ante apreciaciones o valoraciones interesadas, a través de la documentación conocemos una versión de los hechos. Del informe de las aseguradoras se extrae que hubo varios focos de incendio y no uno solo:

El fuego se desarrolló y tuvo su mayor intensidad en la parte de la finca destinada a teatro, sin poder precisar a ciencia cierta el punto en el cual debió empezar. exsisten (sic) otros cuatro focos de incendio que no llegaron a desarrolarse (sic) separados del principal del Teatro, siendo visibles los restos de los que están en las oficinas de Aguas de Gévora y en la escalera que desde la fachada principal sirve a las galerías del teatro, habiendo por contra desaparecido ya, por obra de los inquilinos, los restos de los focos que, nos refieren, estaban en la vivienda del conserje y en las oficinas de las líneas automovilísticas Brito.

En cuanto al desarrollo del incendio, siempre según las apreciaciones que realizaron los peritos de estas compañías aseguradoras: 
[...] por el examen de los restos materiales del incendio deducimos que la techumbre del Teatro, con su armazón de hierro, debió derrumbarse después de estar ardiendo desde bastante tiempo el mobiliario y los pisos puesto que al levantar los escombros no hemos encontrado resto alguno de madera que no fuese reducida a cenizas, lo que no hubiera ocurrido si cubierta y tabiques se hubiesen hundido al poco tiempo de iniciarse el incendio, ya que el material amontonado, hubiera necesariamente ahogado el fuego, por lo menos en algunos sitios.

Después las compañías hicieron apreciaciones interesadas sobre autoría del incendio, con una clara intención de eludir las indemnizaciones:

Esto hace suponer no solamente que el incendio ha sido provocado intencionadamente sino que para que alcanzara tal intensidad y se desarrollara en tal forma tuvo que ser alimentado por materias altamente combustibles.

A continuación, basándose en las opiniones de los vecinos y "cuantas personas se decían enteradas de los hechos ocurrir", detallaron las circunstancias del incendio:

Desde varios días antes del 14 de agosto los locales del Teatro habian sido invadidos por milicianos, quienes lo utilizaban como cuartel y-al parecer-como pequeño puesto de municionamiento (respecto a este último extremo varios testigos manifiestan que mientras duró el incendio se oyeron explosiones como de granadas de mano y cartuchos. El día 6 de agosto una bomba de avión cayó encima del escenario y el día 9 del mismo mes otra explotó en la vidriera de la escalera. Todos los vecinos abandonaron entonces sus viviendas que fueron ocupadas por los milicianos saqueándolas e inutilizando muebles, colchones y ropa. Las puertas de entrada de los pisos presentan todavía señales de violencia. 
La descripción, más propia de un cronista que de un perito de una compañía aseguradora, que debería limitarse a un informe técnico exclusivamente, continuó en estos términos:

El día 14 de agosto por la tarde, al entrar en Badajoz las fuerzas del Ejército Nacional, hubo tiroteo entre los milicianos que disparaban desde la cubierta del Teatro, contra los aviones y desde las ventanas de las viviendas contra las fuerzas del ejército, que respondieron eficazmente, según se puede apreciar todavía por los impactos en las paredes.

Las valoraciones y juicios políticos continúan:

Después del combate y del incendio se encontraron tres cadáveres de rojos en la finca: un sargento muerto de herida en el pasillo del piso segundo, esquina Valdivia a Plaza Minayo, otro, cabo o sargento, caído en el portal de las oficinas de Brito y al cabo de unos días se observó que había otro militar o miliciano muerto en un trozo de la azotea del Teatro, que no se había derrumbado todavía, siendo su cadáver levantado por el inspector del Cuerpo de Seguridad S. Acero.

Debe tenerse en cuenta la descripción interesada que venimos transcribiendo, puesto que este informe se redactó casi un año después de los hechos, concretamente el 7 de junio de 1937. Es decir, los peritos no accedieron al teatro incendiado en los días siguientes con lo que todo lo que registraron en su informe fueron opiniones que recogieron de "cuantas personas se decían enteradas de los hechos ocurridos".

Como estamos viendo, más que un detalle de los daños causados y su valoración, el informe, que lleva por título Acta de Peritación, fue un interesado alegato político:

De las muchas versiones que circulan acerca del origen del fuego, la más verosímil, recogida por la prensa y que 
compartimos, es que este haya sido provocado por los milicianos rojos, al verse perdidos tanto más que varios testigos afirman que el fuego empezó antes de entrar en Badajoz las fuerzas de nuestro ejército. Descartamos por lo tanto la versión, que no tiene confirmación alguna, de que haya sido producida por nuestros soldados, por orden de sus Jefes, para evitar que los rojos, que se hacían fuertes en el Teatro, le produjeran más bajas (Habia caído un sargento de regulares a consecuencia de un disparo hecho desde el interior del Teatro) como también otra, de que haya sido producido por efecto de las bombas de avión, puesto que las pequeñas bombas lanzadas por los aviones, dificilmente podian producir un incendio de tanta magnitud y los varios focos de incendio, antes mencionados, indican claramente que el fuego ha sido provocado intencionadamente.

El informe peritado se cerró con la descripción del teatro, pero sin concretar ni valorar los daños registrados:

[...] el edificio asegurado está situado en la Plaza Minayo esquina Paseo Pi y Margall (hoy del General Franco) dando el otro costado a la calle Rubén Landa (hoy Pedro de Valdivia). Está compuesto de planta baja y dos pisos, destinados a viviendas oficinas y entrada al Teatro, en su parte periférica, siendo destinada al Teatro propiamente dicho su parte central. La construcción es de mampostería y ladrillo, pisos de madera con pavimento de pizarra o baldosín en las viviendas, pavimentos entarimados en el Teatro, revestidos todos inferiormente por cielos rasos de cañizo y cal. La cubierta es de tejas sobre armazón de madera en la parte destinada a viviendas, y de uralita sobre armazón de hierro en el Teatro, uralita sobre armazón de madera en el escenario. Tiene anexsos (sic) sin comunicación, dos pabellones destinado uno a garage (sic) y otro a garage (sic) y taller de reparaciones, de sola planta baja, con paredes de mampostería y ladrillo y cubierta de tejas y ladrillo tubo Bergmanen el Teatro y descubierta 
en las viviendas. La calefacción del Teatro era por agua caliente. La cabina del cine tenía sus puertas de hierro y estaba incomunicada con el interior del Teatro, de acuerdo con lo prescrito en la ley.

Además, 'En el Teatro habían dado en el año último un número de representaciones inferior al que estaba prescrito en la póliza.

El acta de peritación fue firmada por José Almagia Gentilli, vecino de Madrid, nombrado por las compañías aseguradoras y Luis Morcillo Villar, vecino de Badajoz, nombrado por uno de los propietarios del teatro, Manuel de Juan Rodríguez, y se fechó en Badajoz a 7 de junio de 1937, reflejando las apreciaciones realizadas en el lugar de los hechos el día 1 de abril y siguientes.

\section{CONCLUSIÓN}

Hablar de incendios y de teatros ha resultado siempre una combinación llamativa, pero real. Los materiales que se utilizaron para la construcción de los teatros y para sus decoraciones los convertían en pasto seguro de las llamas, dadas las técnicas de iluminación existentes, hasta que se generalizó el uso de la electricidad, a principios del siglo XX.

El Teatro López de Ayala, además de los incendios y conatos de los mismos sufridos como cualquier otro teatro, incluye en su ya dilatada existencia (130 años) un episodio relacionado con el fuego que no tuvo que ver ni con los sistemas de iluminación ni con ninguna causa, digamos, normal o natural.

El teatro de Badajoz fue protagonista, sin quererlo, de la entrada de las tropas nacionales en la ciudad el 14 de agosto de 1936. Se concitan un conjunto de circunstancias adversas que otorgan al Teatro López de Ayala un protagonismo que no buscó. Tuvo la mala suerte de encontrarse a escasos metros de donde se produjo el boquete de la muralla por la que entran los rebeldes (Cuartel de la Bomba, Memoria de Menacho, Puerta del Pilar); tuvo la mala suerte de servir de resguardo a varios milicianos defensores de la ciudad que, en su retirada, se refugian en el Teatro López de Ayala desde el que seguir ofreciendo resistencia; tuvo la mala suerte de ser utilizado como desahogo del odio acumulado y cainita que tantos 
episodios lamentables arrojó la contienda civil.

Hay todavía muchos episodios de la historia de este teatro que son desconocidos por la ciudadanía. Este, referido a su incendio en los inicios de la Guerra Civil y todo lo relacionado con el expediente de su reconstrucción, es uno de ellos.

Hemos querido contribuir a completar esa historia. En la documentación encontrada y comentada, aparte de darse a conocer el expediente abierto por las aseguradoras y la Administración, a requerimientos de la propiedad, hay información sobre un episodio desconocido hasta ahora, pero que forma parte de los tristes y dramáticos acontecimientos que son recordados como la matanza de Badajoz.

\section{REFERENCIAS BIBLIOGRÁFICAS}

DÍEZ BORQUE, J.M. ${ }^{a}$ et alii (1988). Historia del Teatro en España II. Siglos XVIII y XIX. Madrid: Taurus.

PILO ORTIZ, F. et alii (2010). La matanza de Badajoz ante los muros de la propaganda. Madrid: Libros libres.

SEPÚlVEDA, R. (1888). El corral de la Pacheca. Madrid: Librería de Fernando Fe.

SUÁREZ MUÑOZ, Á. (1997). El Teatro en Badajoz: 1860-1886. Cartelera y Estudio. Madrid: Támesis ${ }^{1}$.

(1996). "El teatro en la ciudad de Badajoz en el siglo XIX. Los comienzos". Revista de Estudios Extremeños LII.1, 33-49. (2002). El Teatro López de Ayala. El teatro en Badajoz a finales del siglo XIX [1887-1900]. Mérida: Editora Regional.

(2003). Entre bambalinas. Estampas teatrales. Badajoz: Caja de Badajoz.

SUÁREZ MUÑOZ, Á. y SUÁREZ RAMÍREZ, S. (2002). "Espectáculos parateatrales en Badajoz en el siglo XIX (hasta 1886)". Signa.

Revista de la Asociación Española de Semiótica 11, 257-296. (2006). "El teatro clásico del Siglo de Oro en Badajoz (1860-1900)".

1. Puede verse la tesis de doctorado de Ángel Suárez Muñoz, dirigida por el profesor José Romera Castillo, en la web del Centro de Investigación de Semiótica Literaria, Teatral y Nuevas Tecnologías: http:// www2.uned.es/centro-investigacion-SELITEN@T/pdf/angelsuarez.pdf [20/05/2017]. 
Signa. Revista de la Asociación Española de Semiótica 15, 85-96.

Recibido el 16 de marzo de 2017.

Aceptado el 5 de abril de 2017. 


\section{ANEXOS}

Anexo I: Plano de la ciudad con indicación de la situación del Teatro López de Ayala y escenarios relevantes en la entrada de las tropas rebeldes en la ciudad el 14 de agosto de 1936.

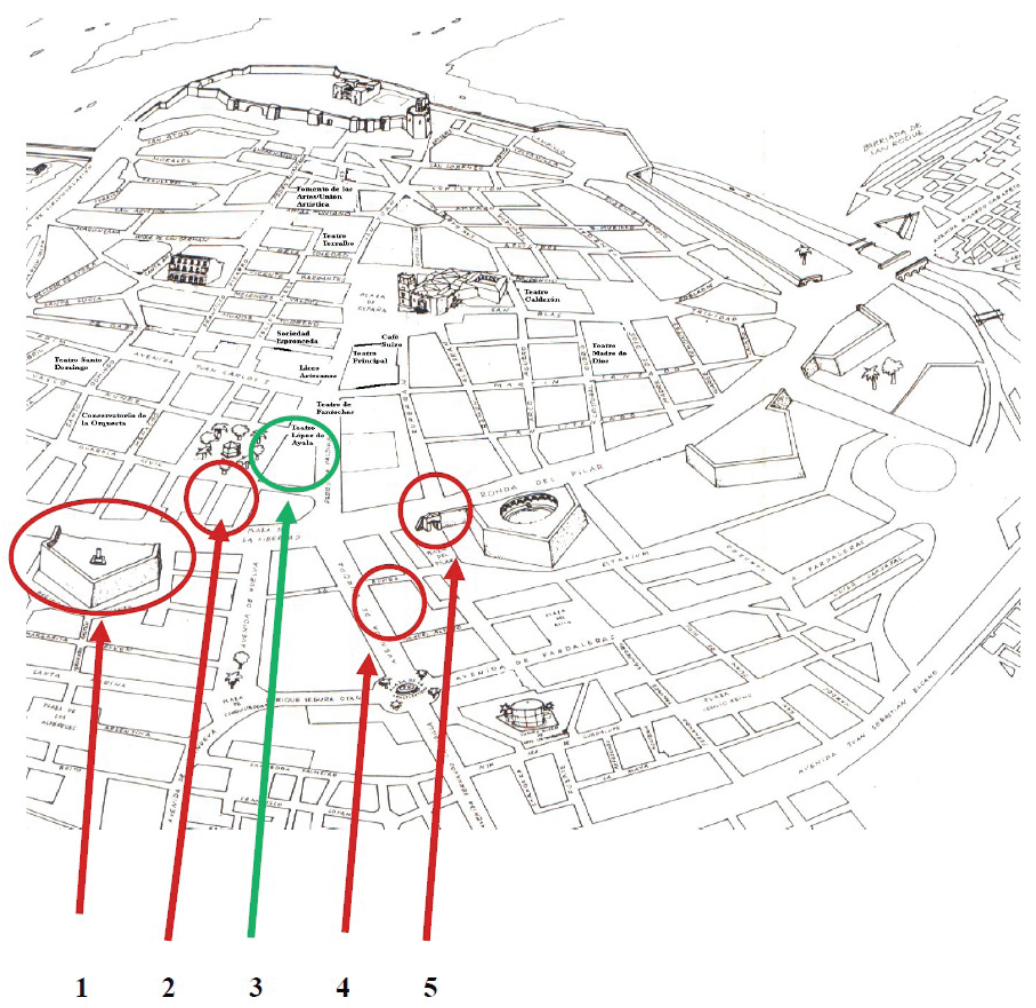

(1) Baluarte de Santiago, conocido popularmente como Memoria de Menacho

(2) Edificio de Correos

(3) Teatro López de Ayala

(4) Cuartel de la Bomba

(5) Puerta Pilar 
Anexo II: Artículo firmado por Jean d'Esme, corresponsal del periódico francés $L$ Intrasigeant publicado el día 27 de agosto de 1936 en su número 20750, página 3 .

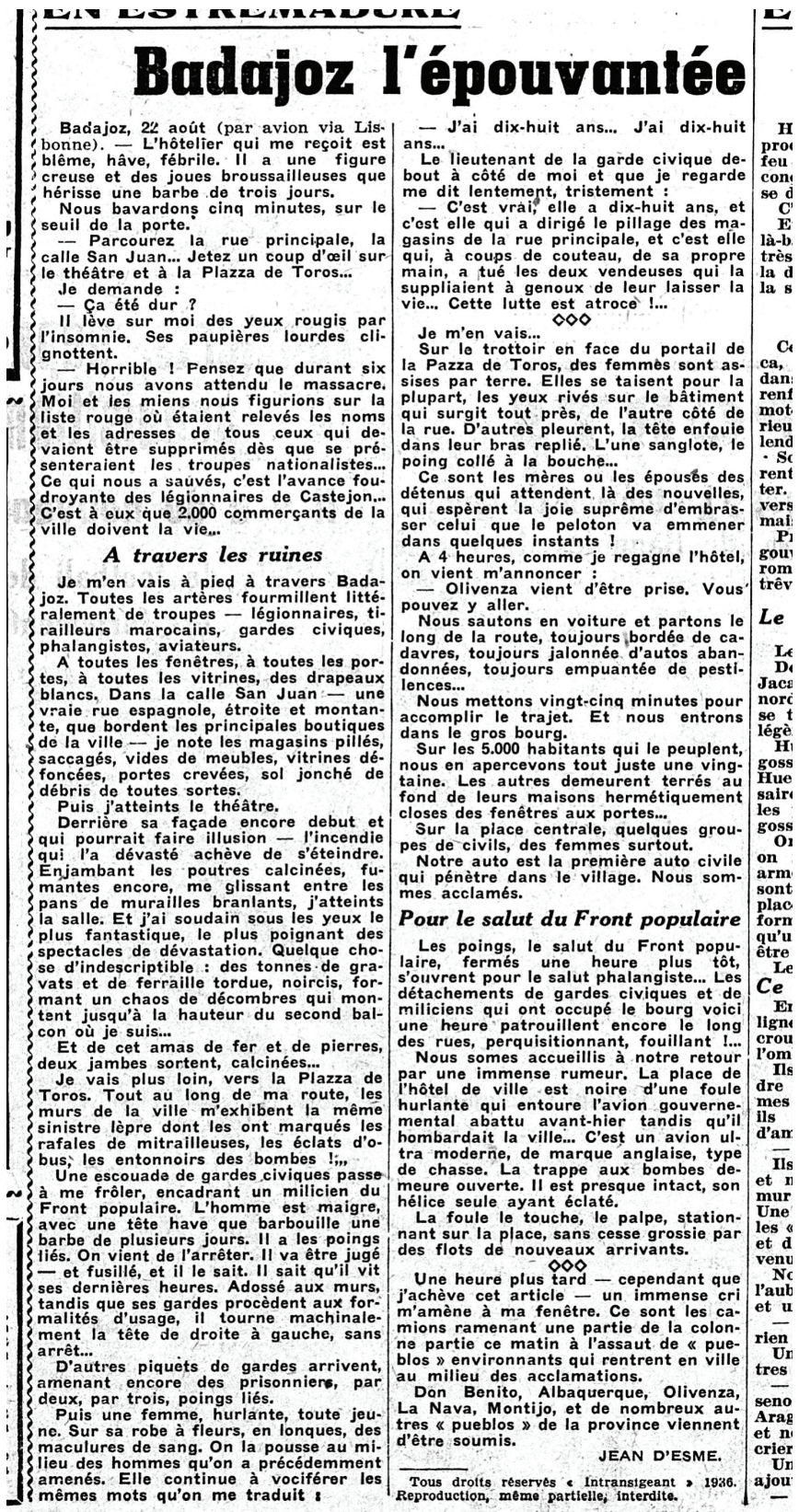


Anexo III: Relación de documento que componen el expediente sobre incendio y reconstrucción del Teatro López de Ayala de Badajoz.

1) Acta de peritación que realizó la Compagnie d'Assurances Generales. Póliza ${ }^{\circ}$ 2919, la Catalana Sociedad Española de Seguros con número de póliza 27582 y Covadonga S.A. de Seguros, con número de pólizas 1872, fechada en Badajoz el siete de junio de 1937.

2) Memoria descriptiva del Proyecto de Reconstrucción del Teatro López de Ayala de Badajoz, fechada en enero de 1938 en Badajoz por el arquitecto Luis Murillo.

3) Informe justificativo del comienzo de las obras de reconstrucción del teatro, firmado por el arquitecto Luis Murillo y fechado en Badajoz el dieciséis de mayo de 1938.

4) Solicitud que dirige el señor César A. Doncel, como agente de cambio y bolsa, en calidad de representante de los propietarios, al Ministro del Interior para que los técnicos del Ministerio inspeccionen el teatro y tasen los daños causados con vistas a autorizar las obras de reconstrucción, fechada en Burgos el treinta y uno de mayo de 1938.

5) Escrito que remite al señor Juan Talavera, como arquitecto Jefe de la Sección Técnica del Servicio Nacional de Regiones devastadas y reparaciones, el secretario de la Comisión, fechado en Sevilla el 14 de julio de 1938, por el que le remite instancia y Proyecto de reconstrucción del teatro.

6) Escrito que remite el señor Juan Talavera al Presidente Delegado de la Comisión de la $4^{\mathrm{a}}$ zona de regiones devastadas y reparaciones, indicando los datos que se precisan para la tramitación del expediente de reconstrucción del teatro, fechado en Sevilla el 20 de julio de 1938.

7) Solicitud que dirige el Presidente Delegado del Servicio de regiones devastadas al señor Delegado de Orden Público de Badajoz, sobre informe reservado que solicita acerca de la conducta social y patriótica, fortuna y medios de vida de D. César A. Doncel, fechado en Sevilla el 22 de julio de 1938.

8) Solicitud que dirige el Presidente Delegado del servicio de regiones devastadas al Alcalde Presidente del Ayuntamiento de Badajoz acerca de si el Teatro López de Ayala puede estar afectado de alguna alineación o proyecto de reforma legalmente aprobado y vigente, firmado en Sevilla también el 22 de julio de 1938. 
9) El mismo Presidente Delegado dirige un escrito al señor Administrador de la Propiedad y Contribución territorial de Badajoz para que certifique el valor que el catastro le tuviera asignado al Teatro López de Ayala antes del 18 de julio de 1936. El escrito de solicitud está fechado en Sevilla también el 22 de julio de 1938.

10) El Presidente Delegado del Servicio de regiones devastadas solicita al señor César A. Doncel el título de propiedad sobre el teatro, declaración jurada sobre su fortuna y demás propiedades (muebles, inmuebles, valores) y cálculo de los daños causados sobre ellos y copia de los planos para completar el expediente, fechado en Sevilla el 22 de julio de 1938.

11) Escrito que dirige el Presidente Delegado del servicio de regiones devastadas al Arquitecto Municipal de Badajoz (Rodolfo Martínez González) para que le remita el aprecio del daño causado en el teatro como consecuencia de la guerra e informe acerca de si la pérdida sufrida en el edificio es total o parcial, así como la vida del inmueble hasta julio de 1936. El escrito está fechado en Sevilla el 22 de julio de 1938.

12) El Presidente Delegado del Servicio de regiones devastadas dirige al Sr. Fiscal de la Vivienda de Badajoz un escrito solicitándole informe sobre si tiene alguna objeción a la reconstrucción del teatro. Lleva fecha de 22 de julio en Sevilla.

13) Escrito que dirige Carlos A. Doncel al Sr. Presidente Delegado del servicio de regiones devastadas respondiendo a sus requerimientos del escrito de fecha 22 de julio (documento 10). Está fechado en Badajoz el 31 de julio de 1938.

14) Escrito que firma el oficial del Catastro en respuesta al documento 9 en el que indica que el valor catastral del edificio teatro a 18 de julio de 1936 era de 674.800 pesetas. Está fechado en Badajoz a 1 de agosto de 1938.

15) El arquitecto municipal certifica que el edificio teatro no está afectado por alineación ni proyecto alguno de reforma. Es respuesta al documento 8 y está fechado en Badajoz el 1 de agosto de 1938.

16) Respuesta de la fiscalía de la vivienda al escrito consignado como documento 12, indicando que no tiene nada que objetar a la reconstrucción del Teatro López de Ayala. Está fechada en Badajoz a 1 de agosto de 1938.

17) Oficio de la Delegación de Hacienda adjuntando valor de la finca Teatro López de Ayala antes del 18 de julio. Está fechado en Badajoz a 1 
de agosto de 1938. Responde al documento 9.

18) Oficio firmado por el alcalde accidental acompañando certificación del arquitecto acerca de que el teatro no se encuentra afectado por alineación o proyecto de reforma, respondiendo al documento al documento 8. Está fechado en Badajoz a 2 de agosto de 1938.

19) Escrito de la Delegación de Seguridad interior, orden público e inspección de frontera por el que se da cuenta de bienes y adhesiones políticas del Carlos A. Doncel, tal y como se solicitaba en el documento 7. Está fechado en Badajoz el 6 de agosto de 1938.

20) Informe que realiza el arquitecto municipal en respuesta al requerimiento consignado como documento 11, acerca de si las pérdidas y daños sufridos por el teatro son totales o parciales. Está fechado en Badajoz a 10 de agosto de 1938 .

21) Es un documento complementario del anterior. Se refiere al informe que eleva el arquitecto municipal sobre las características de la construcción del teatro y los daños sufridos por el incendio. Asimismo realiza estimación sobre el coste de los daños sufridos, concretados en 216.740 pesetas. Está fechado en Badajoz a 10 de agosto de 1938.

22) Oficio de remisión del informe anterior, firmado por el arquitecto municipal y fechado en Badajoz a 10 de agosto de 1938.

23) Declaración jurada que presentan los hermanos Juan, Restituto, Ramona y Luis Rodríguez, propietarios a partes iguales del Teatro López de Ayala, acerca de la finca que poseen, bienes e hipotecas sobre ella. Está fechado en Badajoz a 18 de agosto de 1938.

24) Informe que firma Juan Talavera y que dirige al Sr. Presidente Delegado de la Comisión de la $4^{\mathrm{a}}$ zona de Regiones devastadas y reparaciones acerca de estimar que las obras de reconstrucción del teatro pueden ser autorizadas. Recopila datos que se han ido facilitando en otros documentos. Está fechado en Sevilla el 25 de agosto de 1938.

25) Ficha expediente de la Comisión de la Zona $4^{\mathrm{a}}$, respondiendo a la solicitud de Carlos A. Doncel, en representación de los propietarios del teatro, autorizando las obras de reconstrucción. Está fechada en Sevilla el 26 de agosto de 1938.

26) Informe complementario a la ficha anterior, fechado en Sevilla a 27 de agosto de 1938.

27) Oficio dirigido al Sr. Jefe del Servicio nacional de Regiones Devastadas y Reparaciones, con sede en Burgos, remitiendo el informe 
favorable y expediente para la reconstrucción del teatro. Está fechado en Sevilla el 3 de septiembre de 1938.

28) Respuesta fechada en Burgos el 8 de septiembre con algunas matizaciones y requerimientos al informe sobre reconstrucción del teatro.

29) Oficio devolviendo a los propietarios del teatro la escritura de compraventa, una vez surtidos sus efectos. Fechado en Sevilla el 8 de septiembre de 1938. Está firmado por el Presidente Delegado de la Comisión de la $4^{\mathrm{a}}$ zona y dirigido al alcalde de Badajoz.

30) Oficio comunicando a Carlos A. Doncel que se ha aprobado la reconstrucción del teatro. Está firmado por el Presidente Delegado de la Comisión de la $4^{\mathrm{a}}$ zona. Está fechado en Sevilla el 10 de septiembre de 1938.

31) Escrito que dirige el Presidente Delegado de la Comisión de la $4^{\mathrm{a}}$ zona al Sr. Delegado de Orden Público de Badajoz sobre conducta social y patriótica de los dueños del teatro, tal y como le fueron solicitadas en el documento 28. Está fechado en Sevilla el 12 de septiembre de 1938.

32) Documento manuscrito por Manuel de Juan Rodríguez, uno de los propietarios del teatro, y dirigido a secretario de la Diputación Provincial de Sevilla en el que acusa recibo de la escritura de compraventa que le ha hecho llegar el ayuntamiento de Badajoz. Está fechado en Badajoz a 14 de septiembre de 1938.

33) Oficio del Ayuntamiento de Badajoz en el que se constata la entrega a Manuel de Juan Rodríguez de la escritura de compraventa del teatro. Va dirigido al Presidente de la Diputación de Sevilla. Está fechado en Badajoz a 17 de septiembre de 1938.

34) Escrito que dirige Carlos A. Doncel al Presidente de la $4^{\mathrm{a}}$ Zona de Regiones Devastadas de Sevilla acompañando número del periódico HOY del 18 de agosto de 1936, reproduciendo la fotografía del teatro incendiado y los motivos del mismo. Asimismo remite copia de los informes de dos arquitectos (Luis Morcillo y Almagia Gentilli) por encargo de las compañías aseguradoras, que se niegan a hacer efectiva cualquier cantidad como indemnización a pesar de que, como dice el escrito, 'dicho edificio fue incendiado por los rojos antes de la huida'. Está fechado en Badajoz el 25 de noviembre de 1938.

35) Escrito que dirige Carlos A. Doncel al Presidente de la $4^{\mathrm{a}}$ Zona de Regiones Devastadas de Sevilla comunicando que va a proceder a la reconstrucción del teatro antes de que se elabore una ley de Reconstrucción 
Nacional en la que se incluyan los espacios para espectáculos, por ser necesaria para la población de Badajoz contar con teatro-cine, requerido por las autoridades locales. Comenta que el presupuesto se eleva a un millón de pesetas, que solo cuenta con una pequeña ayuda por parte de la banca de la localidad y, por tanto, figure en la lista para que el día que dicha ley sea un hecho pueda contar con fondos del Estado para la obra. Está fechado en Badajoz a 25 de noviembre de 1938. 
